\title{
THERMOCHEMICAL CONVERSION OF PLANT BIOMASS IN THE ENERGOTECHNOLOGICAL COMPLEX WITH HEAT RECOVERY
}

\author{
Mykola Zablodskiy $^{1}$ - Andrii Zhyltsov ${ }^{1}$ - Ivan Radko ${ }^{1}$ - Viktor Trokhaniak ${ }^{2 *}$ - S. Pugalendhi ${ }^{3}$ - \\ P. Subramanian ${ }^{3}$
}

\begin{abstract}
${ }^{1}$ Department of Electrical Engineering, Electromechanics and Electrotechnology, National University of Life and Environmental Sciences of Ukraine, Heroyiv Oborony st., 15, Kyiv, Ukraine ${ }^{2}$ Department Heat and Power Engineering, National University of Life and Environmental Sciences of Ukraine, Heroyiv Oborony st., 15, Kyiv, Ukraine

${ }^{3}$ Department of Renewable Energy Engineering, Tamil Nadu Agricultural University, Coimbatore 641 003, India
\end{abstract}

\begin{tabular}{|c|c|}
\hline ARTICLE INFO & Abstract: \\
\hline $\begin{array}{l}\text { Article history: } \\
\text { Received: } 2.12 .2019 . \\
\text { Received in revised form: } 14.5 .2020 . \\
\text { Accepted: } 26.6 .2020 .\end{array}$ & $\begin{array}{l}\text { Basic performance principles of the energotechnological complex } \\
\text { used for thermochemical conversion of plant biomass with the } \\
\text { influence of a magnetic field and high recovery of spent heat } \\
\text { carrier energy have been developed. The concurrent saturation of }\end{array}$ \\
\hline $\begin{array}{l}\text { Keywords: } \\
\text { thermochemical conversion } \\
\text { biomass } \\
\text { thermodynamic models } \\
\text { recovery } \\
\text { numerical simulation }\end{array}$ & $\begin{array}{l}\text { a spent heat carrier in a loading bunker with the steam from } \\
\text { humid biomass aimed at using a certain part of a spent heat } \\
\text { carrier, which is clear from oxygen and nitrogen oxide, and } \\
\text { moisture in thermochemical recovery has been considered as an } \\
\text { important aspect of recuperation processes. A mathematical } \\
\text { model has been developed and the results of numerical }\end{array}$ \\
\hline DOI: https://doi.org/10.30765/er.1554 & $\begin{array}{l}\text { simulation have been presented for determining the distribution } \\
\text { of temperature, velocity and pressure fields in a loading bunker. } \\
\text { Prospective assessment of the engineering solutions developed } \\
\text { for heat energy recovery of a double-flow spent heat carrier has } \\
\text { been conducted. }\end{array}$ \\
\hline
\end{tabular}

\section{Introduction}

Significant energy cost and ecological problems of industrial enterprises are caused by the underuse of heat in technological processes, since heated exhaust is discharged. About $40 \%-65 \%$ of latent heat escapes from heattreating furnaces. There are methods and means to recover the heat of flue gases by means of preheating the material or the process air before feeding them into a furnace, which allows for increasing the coefficient of furnace heat recovery and decreasing fuel utilization and negative ecological impacts.

Gajendra et al. [1] considers the comparison of two exhaust heat recovery ways: electrical power generation and preheating of raw materials and air before feeding them into a furnace. In terms of pay-off, raw material and air preheating is a more advantageous way. Wang et al. [2] presents three thermodynamic models of industrial gas heat recovery and electrical power generation. The hierarchy strategy of energy integration is shown to double effect from electric energy production with fuel conservation. As for inferior fuel, bed ash heat recovery is more important in household waste incineration systems [3]. This study covers the analysis of air pre-heating system productivity (ash cooling), where this air is further replaced with the main combustion air and it is used the houseold waste heat boilers.

The incineration process is simulated assuming the uniformity of mixing cold air for combustion and combustion products. The model is built with the use of GAMBIT software, which fails in the exact results when constructing meshes with the number of points being more than 500. A bunker heating system with removed ash in electric filters due to the heat of exhaust gases is suggested in the [4]. There are methods of indirect heat

\footnotetext{
* Corresponding author.

E-mail address: trohaniak.v@gmail.com
} 
transfer in the heat exchangers [5] that are formed by moduli with hollow steel plates of more than $1 \mathrm{~W} /(\mathrm{m} \bullet \mathrm{K})$ heat-transfer capacity.

The counter-current flow of the spent heat transfer medium in these moduli provides heat transfer to the raw material, which is slowly being mixed during 5-10 minutes under the action of the gravitational force along the surface of the hollow plates [6]. However, there are no scientific papers presenting the results of heat recovery simulation in the plants for distractive energotechnological plant biomass processing, especially under two separate flows of a spent heat carrier.

Concurrent saturation of a spent heat carrier with the steam of preheated and pre-dried humid plant biomass in a loading bunker is considered to be an important aspect of recuperation processes aimed at using a part of a spent heat carrier and moisture in thermochemical conversion. This paper is aimed at the development of the main principles of the energotechnological complex used for thermochemical conversion of plant biomass with the influence of a magnetic field and the simulation of heat energy recovery from spent heat carrier flows.

\section{Material and Method}

The structural flow chart of the energotechnological complex used for thermochemical plant biomass conversion with high spent heat carrier energy recovery is presented in Figure 1. Gas coolant was formed in a technological furnace 1 and it was fed for external heating of a dry distillation chamber 2 and an incineration chamber 3. Chopped biomass was fed to a loading device bunker 4 and was further fed to an extrusion hermetic dry distillation chamber 2 with the help of a feeder, where there was bilateral heating of a biomass layer by means of conductive heat transfer and radiation through the chamber walls and from the external rotor surface of a multipurpose electromechanical converter 5 carried out.

The inductors 6 of an electromechanical converter, which was connected to the source of alternating voltage and frequency, creating rotary magnetic fields. Here, there were eddy currents generated in a solid rotor and they heated the later to $350^{\circ}$. Simultaneously, due to the interaction of a magnetic field and eddy currents, there was an electromagnetic torque created and it rotated the rotor, which moved biomass along the chamber 2 by means of helical blades.

Torque was transmitted to the screw 7 of an incineration chamber with the help of gearing. In a hermetic dry distillation chamber 2 biomass was thermally decomposed into volatile and solid products, however, it still contained a certain amount of oxygen when being loaded. Oxygen is a paramagnetic substance and its insignificant amount is enough to consider water to be para- and diamagnetic system. In the process of water oxidation under the influence of a magnetic field, there are such compounds as free radicals, peroxides and singlet molecular oxygen $\left(\mathrm{O}_{2}^{-}\right)$formed. They are highly reactive and influence the processing of solid carbon-based materials [7].

The corresponding products were created in the first reaction zones relative to a feeder, namely screw pitches, as it is shown in Figure 1, and were considered as the possibility of the dynamic adjustment of plant biomass thermochemical conversion process parameters.

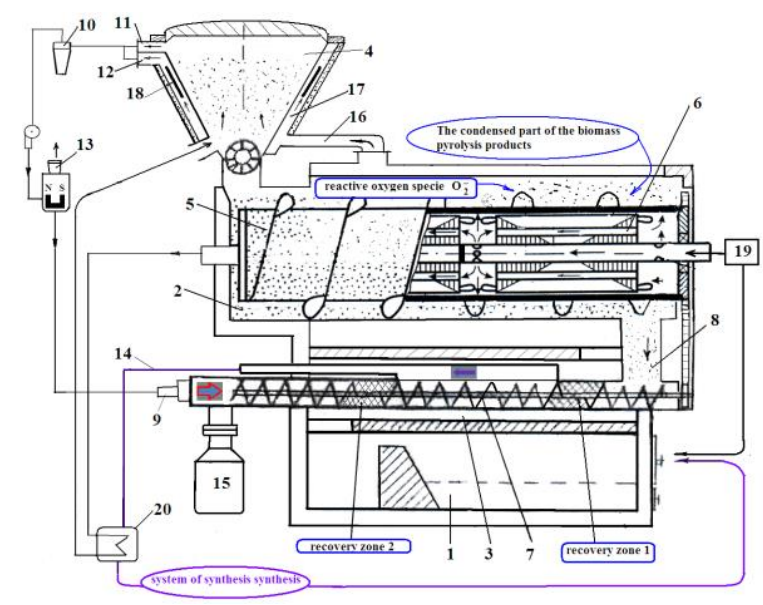

Figure 1. Structural flow chart of energotechnological complex used for thermochemical plant biomass conversion with high spent heat carrier energy recovery. 
The yield of volatile (condensation and uncondensed) biomass pyrolysis products was finished under the temperature of $450-500{ }^{\circ} \mathrm{C}$ and under the intense exothermic reactions taking place in the last flights of a dry distillation chamber (Figure1). Electrical potential difference along eddy-current circuits on the surface of a rotor created the conditions for short-time current flow and the electrolysis of aqueous solutions with partial hydrogen evolution.

The obtained pyrolysis products were fed to an incineration chamber 3 through a reducer 8 , where they passed through a clamped, moving and glowing $\left(800-850{ }^{\circ} \mathrm{C}\right)$ biocarbon bed of the first recovery area (Figure 1), which was created at a flight break point 7. Here, resins and other high-molecular compounds were resolved producing mainly carbon monoxide and hydrogen. Besides, there was an interaction of uncondensed pyrolysis products with carbon and pyrogenetic moisture steam producing $\mathrm{CO}$ and $\mathrm{H}_{2}$ [8]. The main reactions included:

- $\quad$ steam biocarbon gasification reaction

$$
\begin{aligned}
& \mathrm{C}+\mathrm{H}_{2} \mathrm{O}=\mathrm{CO}+\mathrm{H}_{2}-118.7 \mathrm{MJ} / \mathrm{kmol} \\
& \mathrm{C}+2 \mathrm{H}_{2} \mathrm{O}=\mathrm{CO}_{2}+\mathrm{H}_{2}-75.5 \mathrm{MJ} / \mathrm{kmol}
\end{aligned}
$$

- $\quad$ steam conversion reaction

$$
\mathrm{C}+\mathrm{H}_{2} \mathrm{O}=\mathrm{CO}+\mathrm{H}_{2}+43.6 \mathrm{MJ} / \mathrm{kmol}
$$

- $\quad$ Boudouard equilibrium

$$
\mathrm{C}+\mathrm{CO}_{2}=2 \mathrm{CO}-161.5 \mathrm{MJ} / \mathrm{kmol}
$$

The largest part of recovery reactions was the endothermal one, when sensible biocarbon heat is absorbed producing the burning gases $\mathrm{CO}$ and $\mathrm{H}_{2}$, which significantly increased the heating value of the discharge burning gas. Solid fine particles of biocarbon and mineral compounds were retained in the biocarbon bed of the recovery area. After the first recovery area, biocarbon entered the second recovery zone, which is also created at the break point of a screw flight 7 being 1.2-1.5 of its diameter in length, where purified steam-air mixture was fed through an additional air injection pipe 9 against biocarbon flow by means of a vent-off system 10 (cyclone-ventilator).

The purified steam-air mixture came from the output air pipes 11 and 12 of a loading device 4 . Steam cooled down biocarbon along its flow and became overheated. In the second recovery area, it reacted with biocarbon obtaining additional hydrogen. Here, the internal biocarbon surface was better exposed, which increased its quality. In fact, a thermochemical recovery method was applied, that is, the conversion of the output fuel together with combustion products due to the spent gas heat took place. If the reaction proceeded to completion, the fuel (biocarbon) value was increased for 10-15\%. However, if the output substances included oxygen, the level of completion of these reactions was significantly decreased under the same conditions. That is why, we introduced the distribution of a steam-air mixture on the exit from a loading device into two flows as a separate operation: one is discharged into the atmosphere containing larger amounts of oxygen, NO oxide, and the second one was used in thermochemical recovery. For this purpose, a device used for oxygen and nitrogen oxide clearing was applied 13.

The device was based on the method of magnetoconvection. Except for oxygen, nitrogen oxide and nitrogen dioxide, gases were practically non-magnetic, since their volume magnetic susceptibility was two orders lower than that that one of the oxygen. If there was oxygen in a gas medium, under the action of the magnetic field, that is created by permanent magnets or electromagnetic excitation, oxygen was drawn in the direction of the magnetic intensity decrease. That caused the movement of a certain part of the spent air, which contained the maximum amount of oxygen, towards the atmosphere.

The flow discharged into the atmosphere was brought up to the requirements of the boundary permissible emissions by means of traditional approaches. The burning gas from the two recovery areas was directed towards the system of burning gas withdrawal 14 and the cooled biocarbon was accumulated in a bunker 15 . 
In order to improve the unit efficiency, biomass energy utilization rate was increased by means of feeding a part of produced burning gas to a furnace 1 .

This avoided the necessity to lay on natural gas. The installation diagram was more mobile and close to raw material base. Auxiliary gas source was used for the initial ignition. The reduction in heat loses was achieved due to the recovery of a part of spent heat carrier energy and utilization of the heat energy of the burning gas produced in a heat exchanger. A spent heat carrier was fed to the outer annulus 17 of a loading device through a nozzle 16, where there was conductive heating of the discharging biomass performed through a bunker wall. There is a conversion of a part of the sensible heat from a spent heat carrier taking place in the outer annulus of a loading device 4. It was carried out by the method of direct conversion of heat energy into electrical energy by means of a thermoelectric generator 18 .

The electric energy can be further used for feeding a device for spent heat carrier clearing from oxygen and nitrogen oxide. Atmospheric air was supplied from a blowing system 19 into a fixed hollow shaft of a multifunctional electromechanical converter 5 .

The air got into the internal rotor pocket, cooled down inductor active parts 6 and escaped from the other end of a fixed hollow shaft. Here, the air was heated to $+90{ }^{\circ} \mathrm{C}$. Then, the second flow of a spent heat carrier came inside a loading device 4 through a burning gas exchanger 20 , where it was additionally heated to the temperature of $+110^{\circ} \mathrm{C}$.

The estimated air speed should allow for creating the "boiling" layer of the loaded biomass. Heat energy from two spent heat carriers was used for biomass pre-drying and preheating in a loading device, providing a stable mode of biomass heating along a pyrolysis chamber. The initial exothermic reaction temperatures were reached independent of the initial moisture content and additional heat from fuel burning in a furnace was not required.

Simulation of heat recuperation processes in the loading device of a destructive energotechnological plant biomass processing complex was conducted having two separate spent heat carrier flows. Taking into account large loading device dimensions and its axial symmetry, it was decided to apply the design model of one symmetrical half of the device only.

The loading device was made in SOLID WORKS. Afterwards, it was loaded in ANSYS Design Modeler. The boundary conditions were set and the project was passed to ANSYS Meshing. Figure 3 presents the boundary conditions of the loading device. At the inlet boundary (mass-flow inlet, Figure 2a) biomass was loaded at $300 \mathrm{~kg} / \mathrm{h}$ with the air weight part being $180 \mathrm{~kg} / \mathrm{h}$, their temperature was equal to $+20^{\circ} \mathrm{C}$. Figure $3 \mathrm{a}$ also presents the boundary conditions (velocity inlet): the spent heat carrier (flow C) velocity was $6 \mathrm{~m} / \mathrm{s}$ and the temperature was $+400{ }^{\circ} \mathrm{C}$, the velocity of the air, which contained the dissipative component of the energy of an electro-mechanical complex part (flow B), was $5 \mathrm{~m} / \mathrm{s}$ and its temperature was equal to $+100{ }^{\circ} \mathrm{C}$. All the outlet boundaries (Figure $2 \mathrm{~b}$ ) were set relative to pressure. (pressure outlet). The body of a loading device was made of structural low-carbon steel.

Numerical simulation of hydrodynamic processes and heat transfer processes in a loading bunker were conducted. A computational fluid dynamics (CFD) based on ANSYS Fluent software package was used. The mathematical model was based on Navier-Stokes equations $[9,10]$ and the energy-transfer equation applied for convective currents. A standard k- $\varepsilon$ turbulence model [11-13] and Dense Discrete Phase Model (DDPM) were used in the calculations [14]. 


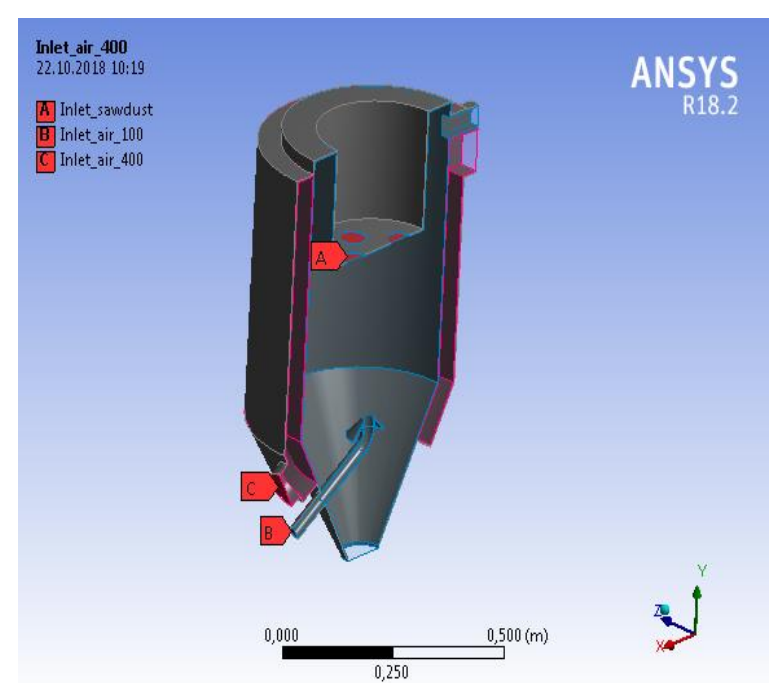

a)

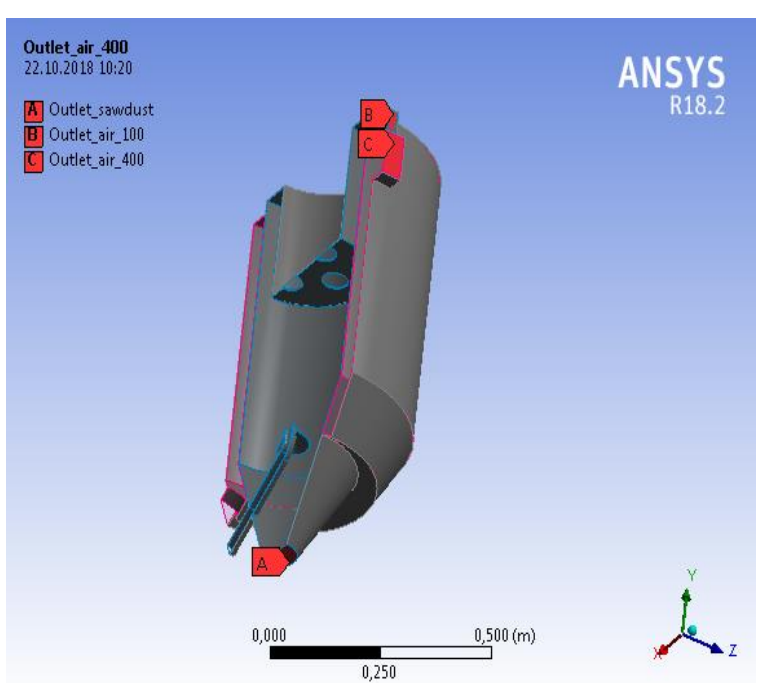

b)

Figure 2. Loader boundary conditions: $a$-inlet; $b$ - outlet.

Navier-Stokes equation:

$$
\left.\begin{array}{r}
\rho\left(\frac{\partial u}{\partial t}+u \frac{\partial u}{\partial x}+v \frac{\partial u}{\partial y}+w \frac{\partial u}{\partial z}\right)=-\frac{\partial p}{\partial x}+\mu\left(\frac{\partial^{2} u}{\partial x^{2}}+\frac{\partial^{2} u}{\partial y^{2}}+\frac{\partial^{2} u}{\partial z^{2}}\right) \\
\rho\left(\frac{\partial u}{\partial t}+u \frac{\partial u}{\partial x}+v \frac{\partial u}{\partial y}+w \frac{\partial u}{\partial z}\right)=-\frac{\partial p}{\partial y}+\mu\left(\frac{\partial^{2} u}{\partial x^{2}}+\frac{\partial^{2} u}{\partial y^{2}}+\frac{\partial^{2} u}{\partial z^{2}}\right) \\
\rho\left(\frac{\partial u}{\partial t}+u \frac{\partial u}{\partial x}+v \frac{\partial u}{\partial y}+w \frac{\partial u}{\partial z}\right)=-\frac{\partial p}{\partial z}+\mu\left(\frac{\partial^{2} u}{\partial x^{2}}+\frac{\partial^{2} u}{\partial y^{2}}+\frac{\partial^{2} u}{\partial z^{2}}\right)
\end{array}\right\}
$$

where $\rho$ - medium density, $\mathrm{kg} / \mathrm{m}^{3} ; \mu$ - medium dynamic viscosity, Pa•s; $\mathrm{p}$ - pressure, Pa; $\mathrm{u}, \mathrm{v}, \mathrm{w}-\mathrm{velocity}$ field of vectors; $\mathrm{t}$ - time, $\mathrm{s}$.

A continuity equation:

$$
\frac{\partial u}{\partial x}+\frac{\partial v}{\partial y}+\frac{\partial w}{\partial z}=0
$$

An energy-conservation equation:

$$
\begin{aligned}
& \rho C_{p}\left(V_{x} \frac{\partial T}{\partial x}+V_{y} \frac{\partial T}{\partial y}+V_{z} \frac{\partial T}{\partial z}\right)= \\
& =\frac{\partial}{\partial x}\left(\lambda \frac{\partial T}{\partial x}\right)+\frac{\partial}{\partial y}\left(\lambda \frac{\partial T}{\partial y}\right)+\frac{\partial}{\partial z}\left(\lambda \frac{\partial T}{\partial z}\right)
\end{aligned}
$$

where $\mathrm{T}$ - point temperature, ${ }^{\circ} \mathrm{K} ; \lambda$ - coefficient of medium heat transfer capacity, $\mathrm{W} / \mathrm{m} \bullet{ }^{\circ} \mathrm{K} ; \mathrm{C}_{\mathrm{p}}-\mathrm{specific}$ heat capacity of a medium, $\mathrm{J} / \mathrm{kg}{ }^{\circ} \mathrm{K}$.

The turbulence kinetic energy, $\mathrm{k}$, and its rate of dissipation, $\varepsilon$, were obtained from the following transport equations: 


$$
\begin{aligned}
& \frac{\partial}{\partial t}(\rho k)+\frac{\partial}{\partial x_{i}}\left(\rho k u_{i}\right)= \\
& =\frac{\partial}{\partial x_{j}}\left[\left(\mu+\frac{\mu_{t}}{\sigma_{k}}\right) \frac{\partial k}{\partial x_{j}}\right]+G_{k}+G_{b}-\rho \varepsilon-Y_{M}+S_{k}
\end{aligned}
$$

And

$$
\begin{aligned}
& \frac{\partial}{\partial t}(\rho \varepsilon)+\frac{\partial}{\partial x_{i}}\left(\rho a u_{i}\right)= \\
& =\frac{\partial}{\partial x_{j}}\left[\left(\mu+\frac{\mu_{t}}{\sigma_{\varepsilon}}\right) \frac{\partial \varepsilon}{\partial x_{j}}\right]+G_{1 \varepsilon} \frac{\varepsilon}{k}\left(G_{k}+G_{3 \varepsilon} G_{b}\right)-C_{2 \varepsilon} \rho \frac{\varepsilon^{2}}{k}+S_{\varepsilon}
\end{aligned}
$$

In these equations, Gk represents the generation of turbulence kinetic energy due to the mean velocity gradients, $G_{b}$ is the generation of turbulence kinetic energy due to buoyancy, $Y_{M}$ represents the contribution of the fluctuating dilatation in compressible turbulence to the overall dissipation rate, $\mathrm{C}_{1 \mathrm{e}}, \mathrm{C}_{2 \mathrm{e}}$ and $\mathrm{C}_{3 \mathrm{e}}$ are constants. $\sigma_{\mathrm{k}}$ and $\sigma_{\mathrm{e}}-$ are the turbulent Prandtl numbers for $\mathrm{k}$ and $\varepsilon$, respectively. $\mathrm{S}_{\mathrm{k}}$, and Se are user-defined source terms.

Lagrange discrete-phase model in ANSYS Fluent corresponded to Euler-Lagrange approach. The level of liquid was considered as a continuum by means of solving Navier-Stokes equations, while a disperse phase was solved by means of tracking a large number of particles, beads or drops according to the estimated flow field. A disperse phase could exchange an impulse, mass and energy with a liquid phase.

For the purpose of biomass loading, Euler DDPM was applied with uniform particle diameter being equal to 8 $\mathrm{mm}$.

$$
\begin{aligned}
& \frac{\partial}{\partial t}\left(a_{p} \rho_{p}\right)+\nabla \cdot\left(a_{p} \rho_{p} \vec{v}_{p}\right)=\sum_{q=1}^{\text {nphases }}\left(\dot{m}_{q p}-\dot{m}_{p q}\right) \\
& \frac{\partial}{\partial t}\left(a_{p} \rho_{p} \vec{v}_{p}\right)+\nabla \cdot\left(a_{p} \rho_{p} \vec{v}_{p} \vec{v}_{q}\right)= \\
& =-a_{p} \nabla p+\nabla \cdot\left[a_{p} \mu_{p}\left(\nabla \vec{v}_{p}+\nabla \vec{v}_{p}^{T}\right)\right]+ \\
& +a_{p} \rho_{p} \vec{g}+F_{v m, l i f t, u s e r}+ \\
& +\sum_{q=1}^{n p h a s e s}\left[\vec{K}_{q p}\left(\vec{v}_{q}-\vec{v}_{p}\right)+\dot{m}_{q p} \vec{v}_{q p}-\dot{m}_{p q} \vec{v}_{p q}\right]+ \\
& +K_{D P M}\left(\vec{v}_{D P M}-\vec{v}_{p}\right)+S_{D P M, \exp l i c i t}
\end{aligned}
$$

Here, equation 6 is the mass conservation equation for an individual phase $p$ and equation 7 is the corresponding momentum conservation equation. The momentum exchange terms (denoted by DPM) are split into an explicit part, SDPM, explicit, and an implicit part, in which vDPM represents the particle averaged velocity of the considered discrete phase, KDPM and represents its particle averaged interphase momentum exchange coefficient [15]. Currently, these momentum exchange terms are considered only in the primary phase equations.

\section{Results and discussion}

The geometry was arranged in actual size. The number of elements and faces was quite large (Table 1). Taking into account rather large bunker dimensions, the size of the element and the face was increased insignificantly because of the limited productive and calculating computer capacity. 
Table 1 presents the mesh settings in ANSYS Meshing needed for further transfer of heat- and mass-exchange and hydrodynamics calculations to ANSYS Fluent.

Figure 3 presents the generated mesh of a loading bunker. The mesh is insignificantly reduced relative to the rest of the wall area. This allows for providing the improved calculation of hydrodynamics. The mesh is clearly viewed in section. It allows for better evaluation of the quality and the disadvantages of the mesh itself. In addition, there is condensation of the mesh observed near the walls due to the improvement of the mesh quality according to the orthogonal quality criterion [16].

Table 1. Parameters for generating a mesh for a loading bunker.

\begin{tabular}{|l|c|c|}
\hline \multicolumn{1}{|c|}{ Settings } & Unit & Drier \\
\hline $\begin{array}{l}\text { Mesh performance index } \\
\text { (orthogonal quality) }\end{array}$ & - & 0.45 \\
\hline Number of elements & pcs & 5637743 \\
\hline Number of point & pcs & 1017288 \\
\hline Angle curvature & deg & 36 \\
\hline Method & - & Tetrahedrons \\
\hline Maximum element size & $\mathrm{m}$ & $8.268 \cdot 10^{-3}$ \\
\hline Maximum face size & $\mathrm{m}$ & $3.3073 \cdot 10^{-2}$ \\
\hline Minimum face size & $\mathrm{m}$ & $1.6536 \cdot 10^{-4}$ \\
\hline
\end{tabular}
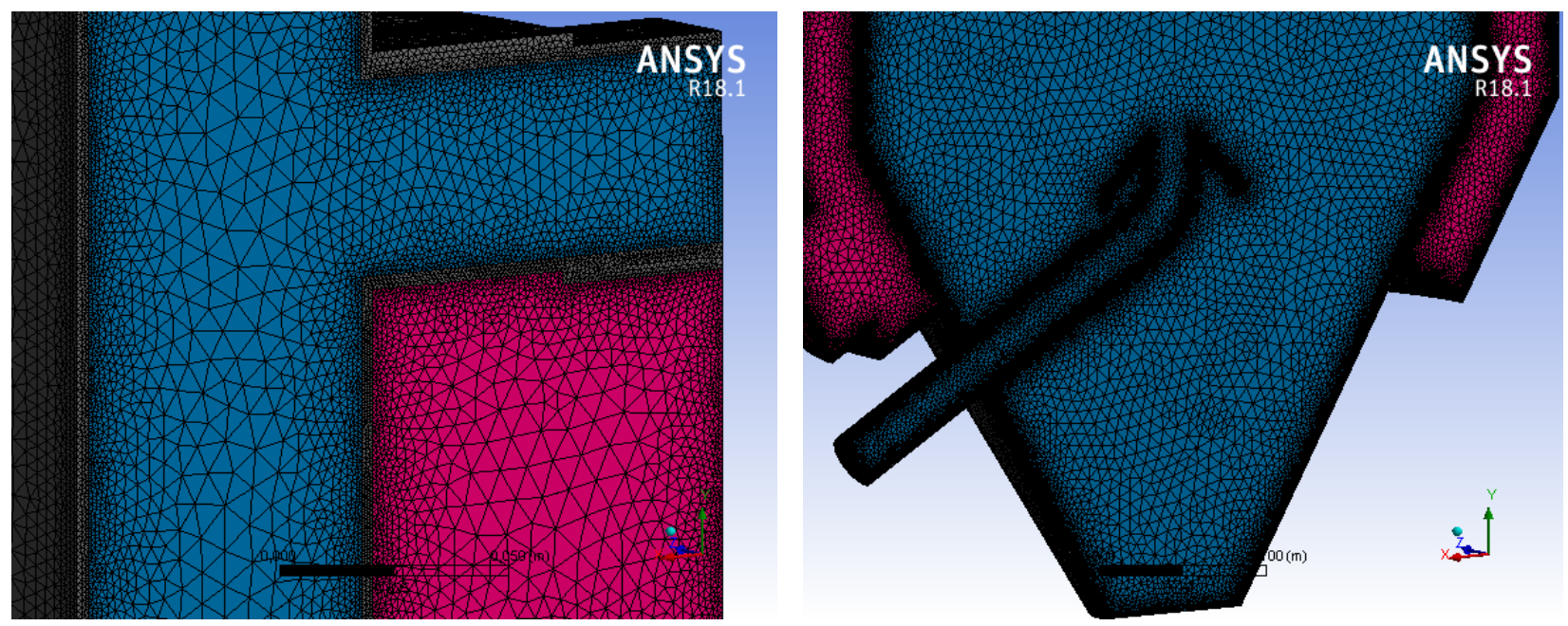

Figure 3. Mesh generation of a pre-drying and pre-heating loading device.

Figure 4-8 presented the main modeling results. The boundary field of biomass and air temperatures is presented in Figure 4. The inlet temperature of the air, which contained the dissipative component of the energy of an electro-mechanical complex part (Figure 4a), was $+100{ }^{\circ} \mathrm{C}$ and, due to the air gap in the upper zone, this air reached the temperature of $+120{ }^{\circ} \mathrm{C}$. When leaving the outer annulus of a loading device, a spent heat carrier (Figure 4b) had the velocity of $6 \mathrm{~m} / \mathrm{s}$ and the temperature of $+400{ }^{\circ} \mathrm{C}$. During the flow it was distributed by volume having the average temperature within the range of $+290-+310{ }^{\circ} \mathrm{C}$. The temperature of the bulk biomass in the bottom of a loading device bunker was equal to $+40-+50{ }^{\circ} \mathrm{C}$. 


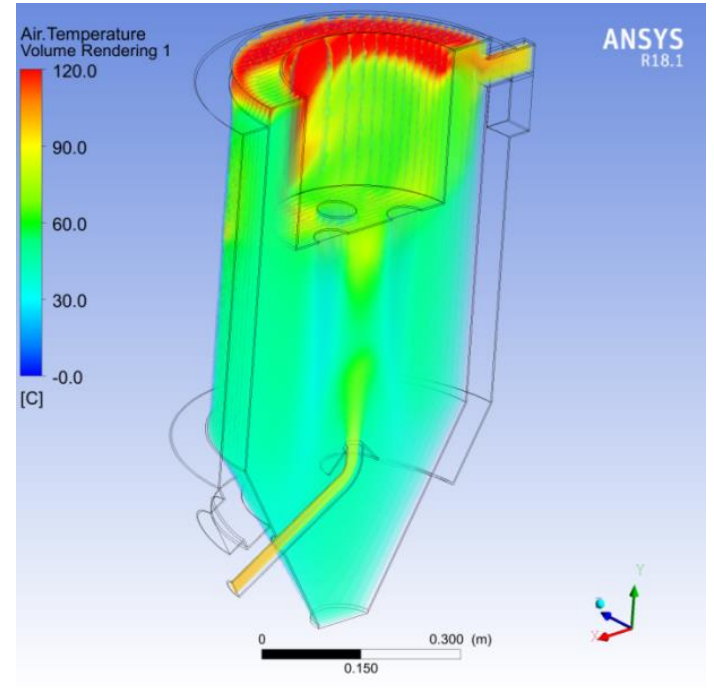

a)

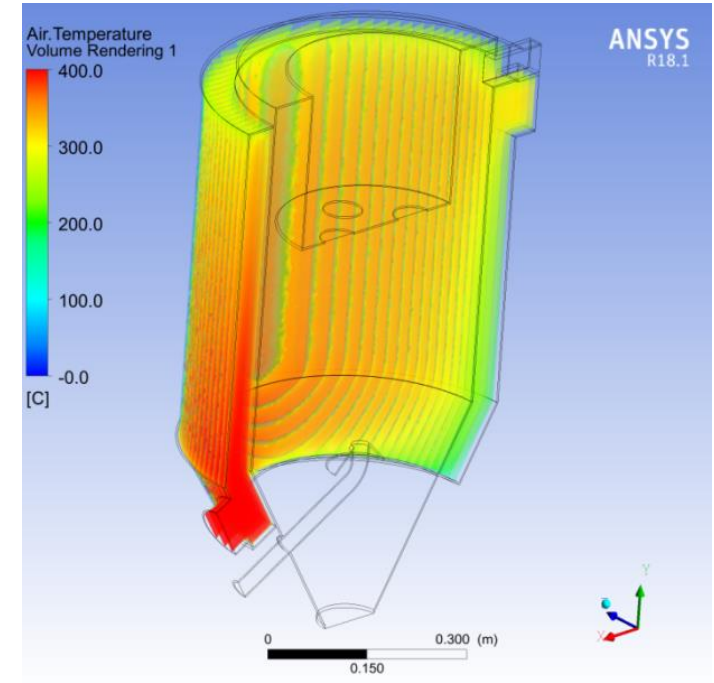

b)

Figure 4. 3D temperature field, ${ }^{\circ} \mathrm{C}: a$-in a raw material loading area, $b$-in the area of a spent heat carrier flow.

Figure 5 presented differential pressure in the channels. Referring to biomass, the maximum pressure was equal to $80 \mathrm{~Pa}$ (Figure 5a), as for spent heat carrier gasses, it was equal to $4750 \mathrm{~Pa}$ (Figure 5b).

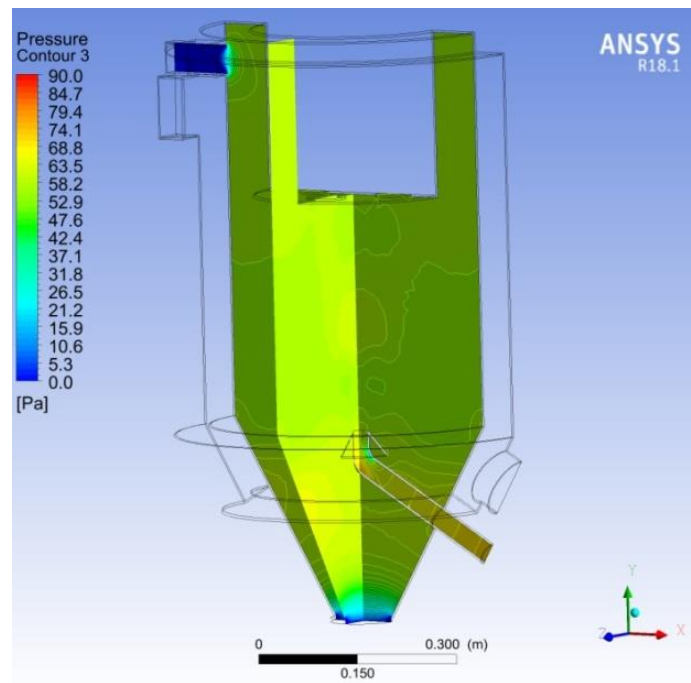

a)

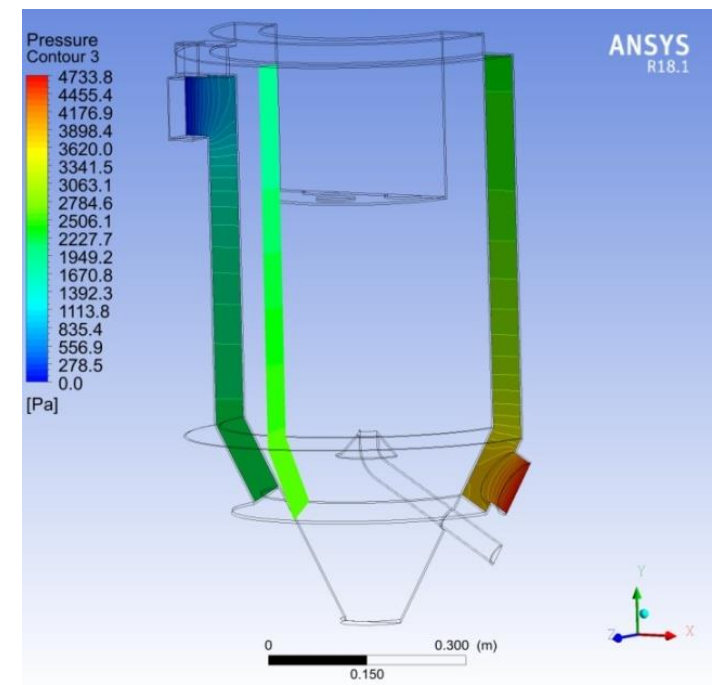

b)

Figure 5. Boundary pressure field, Pa: $a$ - in a raw material loading area, $b$-in the area of a spent heat carrier flow.

Figure 6 presented air velocity in the two spent heat carrier flows. The maximum biomass velocity was equal to $10.2 \mathrm{~m} / \mathrm{s}$ at the outlet. Biomass and air entered a loading device with the velocity ranging from 6 to 8 $\mathrm{m} / \mathrm{s}$. The average biomass velocity was equal to $3.7 \mathrm{~m} / \mathrm{s}$ and the average spent heat carrier velocity was $2.4 \mathrm{~m} / \mathrm{s}$. Figure 7 presented air and biomass current lines. The air with the inlet velocity being $6 \mathrm{~m} / \mathrm{s}$ rose together with biomass for a short distance due to batch biomass feeding (Figure 7a). That is why, during the experimental testing, it was to the point to increase the inlet air velocity to $9-10 \mathrm{~m} / \mathrm{s}$ in order to provide more effective biomass mixing. Exhaust gases slowly flew about the walls of the external shell (Figure7b). 


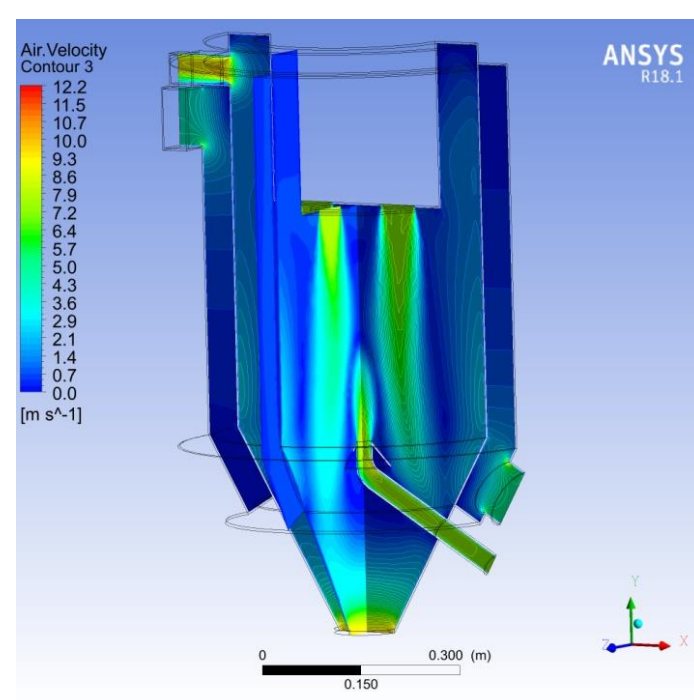

a)

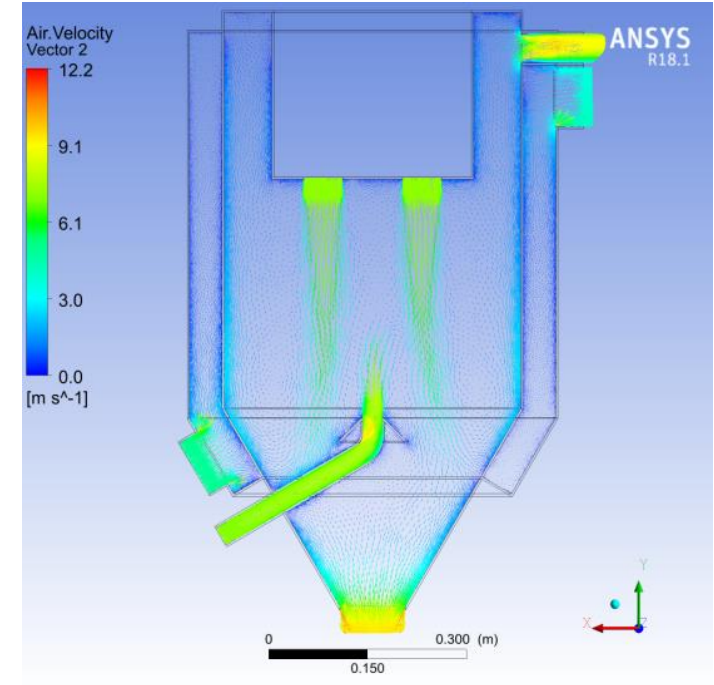

b)

Figure 6. Velocity field (a) and velocity vector (b) of the two heat carriers, $\mathrm{m} / \mathrm{s}$.

Figure 7 presented the current lines of biomass and air with their part entering the upper channel. Here, biomass loss might be equal up to $4 \%$. In order to prevent the loss, it was necessary to reduce the volume fraction of air at the biomass inlet.

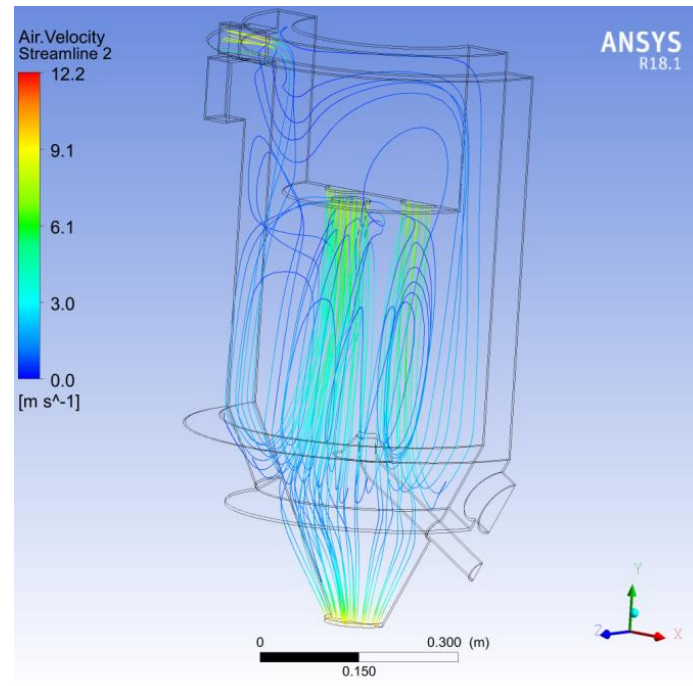

a)

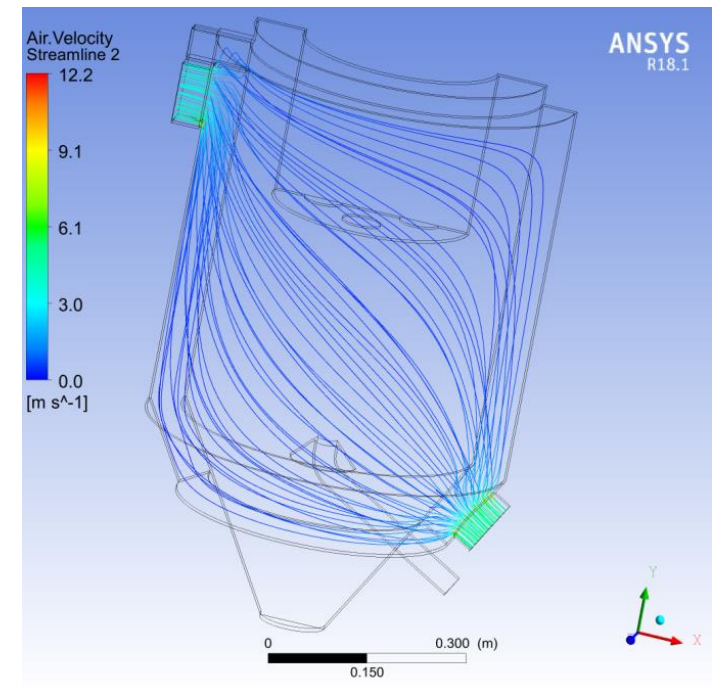

b)

Figure 7. Current flow lines at the inlet of biomass loader (a) and in the area of spent heat carrier flow (b), $\mathrm{m} / \mathrm{s}$.

Figure 8 presented the volume fraction of biomass in a loading device. At the entry to a loader, there was biomass thickness observed. In order to reduce the dead area, it was recommended to enlarge a biomass outlet opening and, thus, reduce biomass and air outlet velocity (see Figure 7a). 

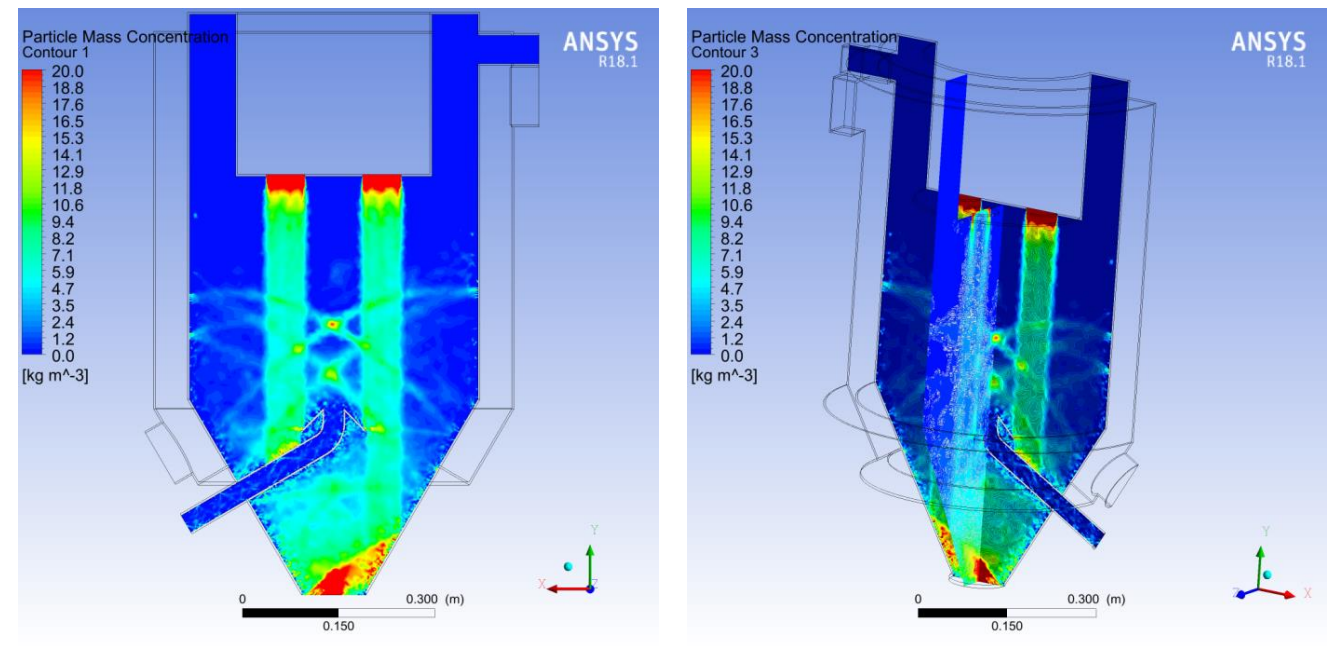

Figure 8. Mass concentration in a biomass loading device, $\mathrm{kg} / \mathrm{m}^{3}$.

When being moved in a loading device, in the near-wall zones biomass was heated to $+60{ }^{\circ} \mathrm{C}$ and within $70 \mathrm{~s}$ there was a drop in its relative moisture from $60 \%$ to $50-52 \%$. In order to reduce heat losses, it was recommended to install insulation of the external chamber. The initial testing of the biomass thermochemical conversion experimental plant (Figure 9) verified the main electromagnetic and thermodynamic characteristics of the processes that took place in a dry distillation chamber, an incineration chamber and a loading device.

Table 2 presents the comparative results of the numerical simulation and the experimental investigations in a loading biomass bunker. The reference absolute error of measuring air speed was $(\mathrm{V}): \pm(0,1+0,05 \cdot \mathrm{V})$ $\mathrm{m} / \mathrm{s}$. Temperature measuring was conducted by previously calibrated thermocouples. The permissible calibration error was $\Delta \mathrm{t}=1{ }^{\circ} \mathrm{C}$. Pressure was measured by a U-tube manometer, the boundary error of the measuring kit when measuring air was equal to $8.8 \%$. The spread of the main results of the numerical simulation and the experimental investigations did not exceed $12 \%$.

Table 2. Comparative results of the numerical simulation and the experimental results in a loading biomass bunker.

\begin{tabular}{|c|c|c|c|c|}
\hline Parameters & Unit & Boundary conditions & Simulation & Experiment \\
\hline \multirow[t]{6}{*}{ Air Temperature } & \multirow[t]{6}{*}{${ }^{\circ} \mathrm{C}$} & interior-part-air_100* & 29.99661 & 34.2 \\
\hline & & interior-part-air_400** & 230.6009 & 241.0 \\
\hline & & interior-part-steel $* * *$ & 48.234762 & - \\
\hline & & outlet_air_100 & 25.88125 & 28.2 \\
\hline & & outlet_air_400 & 158.41693 & 164.0 \\
\hline & & outlet_sawdust & 26.849684 & 30.4 \\
\hline \multirow[t]{8}{*}{ Air Total Pressure } & \multirow[t]{8}{*}{$\mathrm{Pa}$} & interior-part-air_100 & 49.95556 & - \\
\hline & & interior-part-air_400 & 25.25299 & - \\
\hline & & inlet_air_100 & 152.43279 & 166.0 \\
\hline & & inlet_air_400 & 42.473424 & 37.4 \\
\hline & & inlet_sawdust & 75.042718 & - \\
\hline & & outlet_air_100 & 30.938241 & 33.0 \\
\hline & & outlet_air_400 & 14.831086 & 16.6 \\
\hline & & outlet_sawdust & 47.571398 & - \\
\hline \multirow{5}{*}{$\begin{array}{l}\text { DPM Concentration } \\
\text { mixture }\end{array}$} & \multirow[t]{5}{*}{$\mathrm{kg} / \mathrm{m}^{3}$} & interior-part-air_100 & 1.3840888 & - \\
\hline & & inlet_air_100 & 11.263658 & - \\
\hline & & inlet_air_400 & 0 & - \\
\hline & & inlet_sawdust & 209.39009 & 238.0 \\
\hline & & outlet_sawdust & 6.0712342 & - \\
\hline
\end{tabular}




\begin{tabular}{|c|c|c|c|c|}
\hline \multirow[t]{8}{*}{ Air Velocity Magnitude } & \multirow[t]{8}{*}{$\mathrm{m} / \mathrm{s}$} & interior-part-air_100 & 1.2689532 & - \\
\hline & & interior-part-air_400 & 0.91500271 & - \\
\hline & & inlet_air_100 & 5 & - \\
\hline & & inlet_air_400 & 5.9999998 & - \\
\hline & & inlet_sawdust & 6.4973829 & - \\
\hline & & outlet_air_100 & 6.8623317 & 7.3 \\
\hline & & outlet_air_400 & 4.3409317 & 4.8 \\
\hline & & outlet_sawdust & 8.6530965 & - \\
\hline \multirow[t]{9}{*}{ Air Total Energy } & \multirow[t]{9}{*}{$\mathrm{j} / \mathrm{kg}$} & interior-part-air_100 & -403171.2 & - \\
\hline & & interior-part-air_400 & -201258.78 & - \\
\hline & & interior-part-steel & -32955.643 & - \\
\hline & & inlet_air_100 & -332781.94 & - \\
\hline & & inlet_air_400 & -30859.402 & - \\
\hline & & inlet_sawdust & -413227.45 & - \\
\hline & & outlet_air_100 & -406986.3 & - \\
\hline & & outlet_air_400 & -273567.98 & - \\
\hline & & outlet_sawdust & -406260.81 & - \\
\hline
\end{tabular}

The conducted numerical simulation resulted in obtaining additional results' values (Table 2) of a heatand mass-exchange process in a loading biomass bunker. This offered the possibility to make further improvements of this design. Further, biomass processing modes were to be optimized and improved.

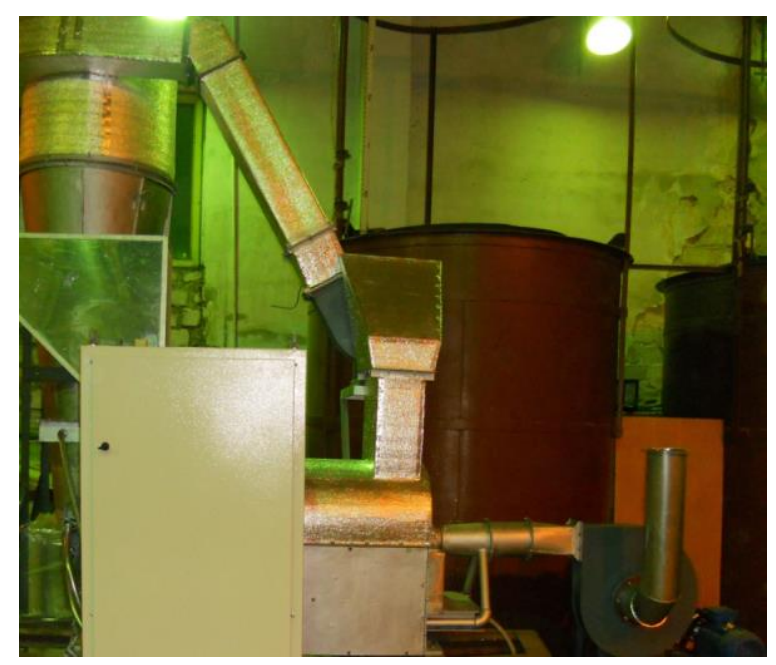

Figure 9. The biomass thermochemical conversion experimental plant.

\section{Conclusion}

The main operation principles of the energotechnological complex used for thermochemical plant biomass conversion under the influence of a magnetic field and high recovery of spent heat carrier energy have been developed. The concurrent saturation of a spent heat carrier with the steam from humid biomass in a loading bunker aimed at using a certain part of a spent heat carrier, which is clear from oxygen and nitrogen oxide, and moisture in thermochemical recovery has been considered as an important aspect of recuperation processes. The conducted numerical simulation allows the determination of temperature distribution, velocity and pressure fields in a loading bunker and evaluating the prospects of the engineering solutions developed for the heat energy recovery of a double-flow spent heat carrier has been conducted.

\section{Acknowledgments}

Supported by Ministry of Education and Science of Ukraine (Kyiv), Ukrainian-Indian Project No. M/372019. 


\section{References}

[1] Gajendra, K. Gaurav, Shabina, K.: Profitability analysis of power generation using waste heat of sponge iron process, Energy, 141 (2017), 333-347.

[2] Wang, Y, Niu, Y, Zhang, X, Wang, Z, Wang, S, Hui, S.: Optimization and energy integration of heat recovery and power generation system, Applied Thermal Engineering, 107 (2016), 294-300.

[3] Zakariya, K.: Combustion Air Pre-heating from Ash Sensible Heat in Municipal Waste Incineration Systems, Research Journal of Applied Sciences, Engineering and Technology, 7 (2014), 3, 551-558.

[4] Sundarrajan,.S, S.Mohammed Shafee: Energy Conservation in Power plant Electrostatic Precipitator (ESP) by Using Waste Heat Recovered from Boiler, International Journal of Innovative Research in Science, Engineering and Technology. 4 (2015), 2, 665-669.

[5] Gorobets, V., Bohdan, Y., Trokhaniak, V., Antypov, I.: Experimental studies and numerical modelling of heat and mass transfer process in shell-and-tube heat exchangers with compact arrangements of tube bundles, MATEC Web of Conferences, 240 (2018), 02006.

[6] Solex thermal science INC.250, 4720 - 106 AVE. S.E. Calgary, Alberta, Canada, T2C 3 G5. www.solexthermal.com

[7] Jalil Arif M.: Temperature Air/Steam Gasification (HTAG) Of Biomass - Influence of Air/Steam flow rate in a Continuous Updraft Gasifier, Stockholm, 2013

[8] Sklyarenko, E. V., Bileka, B. D.: Experimental Study of Thermochemical Conversion Process for Plant Biomass into Combustible Gas and Biocarbon on Installation of Screw Type, Energy Technologies \& Resource Saving, 2 (2016), 43-49.

[9] Khmelnik, S. I.: Navier-Stokes equations. On the existence and the search method for global solutions, Mathematics in Computers, MiC, Bene-Ayish/Israel; 2018.

[10] Trokhaniak, V., Klendii, O.: Numerical simulation of hydrodynamic and heat-mass exchange processes of a microclimate control system in an industrial greenhouse, Bulletin of the Transilvania University of Brasov, Series II: Forestry, Wood Industry, Agricultural Food Engineering, 11 (2018), 12, 171-184.

[11] Bardina, J. E., Huang, P. G., Coakley, T. J.: Turbulence Modeling Validation, Testing and Development, NASA reports, California, 1997.

[12] Hanjalic, K.: Advanced Turbulence Closure Models: A View on the Current Status and Future Prospects, Int. J. Heat \& Fluid Flow, 15 (1994) 178-203.

[13] Speziale, C. G., Gatski, T., Hussaini, M., Lumley J.: Modeling of Turbulent Transport Equations. Simulation and Modeling of Turbulent Flows, Oxford University - Press, 1996.

[14] ANSYS: ANSYS Fluent Theory Guide, USA, 2017.

[15] Cloete, S., Johansen, S. T., Braun, M., Popoff, B., Amini, S.: Evaluation of a Lagrangian Discrete Phase Modeling Approach for Application to Industrial Scale Bubbling Fluidized Beds, Proceedings of the 2011 10th International Conference on Circulating Fluidized Beds and Fluidization Technology, Sun River, Oregon USA, 2011, 1-9.

[16] Gorobets, V. G., Trokhaniak, V. I., Antypov, I. O., Bohdan, Yu. O.: The numerical simulation of heat and mass transfer processes in tunneling air ventilation system in poultry houses, INMATEH: Agricultural Engineering, 55 (2018), 2, 87-96. 